\title{
Uma abordagem centrada no usuário para a produção de filmes para televisão sobre medicamentos
}

\author{
A user-centred approach to the production of television broadcasting spots about \\ medicines
}

design da informação, bulas de medicamentos, campanhas televisivas

\begin{abstract}
Campanhas televisivas que informem sobre medicamentos de forma não comercial são essenciais para o esclarecimento da população sobre o tema, promovendo uma consciência crítica sobre a qualidade legal e informacional no uso de medicamentos. Este artigo apresenta os resultados do desenvolvimento de instrumentos de comunicação televisivos - filmes - sobre a bula de medicamentos com abordagem centrada no usuário. Inicialmente, foi realizada uma pesquisa visando propor recomendações para a produção dos filmes, através de analise de similares, entrevistas e grupo focado. Baseados nos resultados/recomendações foram definidos o conteúdo e apresentação gráfica para produção dos filmes. Após a produção da campanha, foi realizada uma avaliação junto ao usuário, através de grupo focado, observando a compreensão das mensagens veiculadas e a satisfação com as mesmas. Os resultados desta validação permitiram ajustes necessários para aprimoramento dos protótipos de vídeos que estarão disponíveis para veiculação na Televisão Universitária da UFPR e pela ANVISA/Ministério da Saúde.
\end{abstract}

information design, medicine inserts, television campaigns

Television campaigns on medicines in a non-commercial approach are relevant to inform people about this theme, promoting people's awareness regarding information and legal quality on medicine use. This paper presents the partial results of the development of communication instruments for television - spots - on medicine inserts with a user-centred design approach. Initially, a research was conducted to propose recommendations to the spots production, through spot sample analysis, interviews and focus group. Based upon the results/recommendations the spots' contents and graphic presentation were defined...

\section{Introdução}

A mídia televisiva no Brasil tem sido usada para veiculação de informações sobre medicamentos, atendendo principalmente aos interesses comerciais da indústria farmacêutica. A maioria das peças publicitárias veiculadas não é esclarecedora sobre o uso e implicações dos medicamentos comercializados. Segundo Wzorek (2005), em 1012 publicidades de produtos farmacêuticos, $78,16 \%$ estavam em desacordo com a legislação (ANVISA), apresentando em média 4,6 infrações por peça publicitária. Esses dados reforçam a necessidade de ampliação das ações educativas em saúde para a população. Neste sentido, instrumentos de comunicação televisivos que informem corretamente os cidadãos sobre o uso de medicamentos de forma não comercial tornam-se essenciais para a conscientização da população sobre este tema.

O presente artigo apresenta resultados de estudo sobre a concepção, prototipagem e avaliação de instrumentos de comunicação televisivos que informem corretamente os cidadãos sobre o uso de medicamentos. O estudo é parte do Projeto InfoBula que propõe uma metodologia para desenvolvimento, avaliação e disseminação de informações sobre bulas de medicamentos no Brasil. Este estudo utiliza uma abordagem centrada no usuário, combinando aspectos analíticos e experimentais, heurísticos e empíricos, com os seguintes objetivos: (a) desenvolver diretrizes para produção de instrumentos televisivos (filmes) - voltada para informação e educação do cidadão sobre bulas de medicamentos; (b) conceber e prototipar um conjunto de filmes passíveis de veiculação em uma campanha pública; e (c) avaliar a eficácia comunicacional dos filmes produzidos junto à população. 


\section{Fundamentação teórica}

Documentos públicos são considerados problemáticos e têm atraído o interesse de designers de documentos e analistas de discurso. Quando uma companhia ou organização comunica-se com o público geral (i. e. governo, polícia, bancos, etc.), onde tais documentos emitidos variam consideravelmente (i. e. multas, pagamentos de impostos, manuais de instrução, formulários, etc.) ocorre a comunicação pública (Askehave e Zethsen, 2003).

Segundo as autoras, as principais características desse tipo de comunicação, onde algumas esbarram nos conceitos de comunicação de massa, seriam: (a) Distribuição e recepção em largaescala: são designadas para grande parte da população; (b) Audiência heterogênea: devido ao grande alcance vários públicos diferentes são atingidos; (c) Relação assimétrica entre emissor e receptor: geralmente quem compõe as informações são especialistas no assunto e quem recebe é, geralmente, inexperiente; (d) Interação impessoal e anônima: o receptor desconhece o emissor; (e) Interação controlada pelo emissor: comunicação unilateral; (f)comunicação mediada por gênero: ao contrário da comunicação em massa, onde há transmissão por rádio, televisão, revistas, etc., na comunicação pública o meio é escolhido com base no gênero e no propósito ao qual se destina, podendo ser através de cartas, formulários, manuais, etc.; (g) Afinidade regulatória: geralmente regulados por leis, diretrizes e burocracias; (h) Gênero funcional: a grande diferença entre comunicação pública e comunicação em massa estaria aqui: a função: o uso que o receptor faz da mensagem.

Materiais educativos também devem ser desenvolvidos pela ótica da comunicação pública, porém esta educação costuma ser feita de forma inadequada e desinteressante para o público ao qual é direcionada; Yamanoue et al. (2005) acreditam que materiais visuais que representem literalmente o problema são mais eficazes no entendimento e solução dos mesmos.

Um modelo estrutural (Figura 1), a partir da perspectiva da comunicação visual e da alfabetização visual, foi proposto por Pettersson (1982). O autor afirma que os modelos anteriores falham ao incorporar o processo perceptivo: a percepção da mensagem pelo receptor varia em função de seu status sócio-cultural, sua experiência, humor, processo cognitivo e nível de desenvolvimento. Assim como o receptor pode entender a mensagem como "lixo" (i.e., dispensável, fora de seu interesse), pode também entender corretamente, agir e responder ao emissor.

Figura 1: Modelo de comunicação proposto por Pettersson (1982)

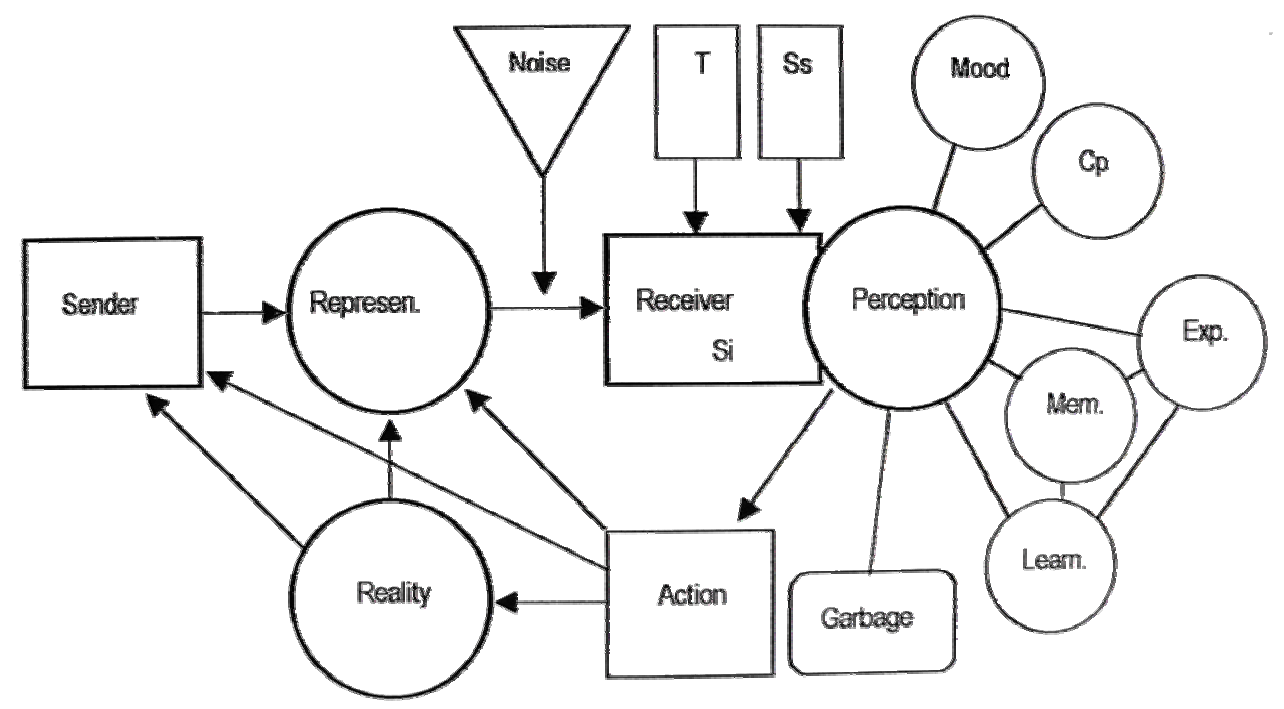

$\mathrm{T}=$ Time and stages of development, $\mathrm{Ss}=$ Cultural and social status, Represen. = Representation, Si = Sensory impression, $\mathrm{Cp}=$ Cogritive processes such as intelligence and creativity, Exp. $=$ Experience, Leam. $=$ Leaming, and Mem. $=$ Memory.

No que diz respeito a cultura e comunicação, Lange (2000) por sua vez, argumenta que a cultura tem um sentido amplo e está presente na maioria das facetas da vida de uma pessoa. São alguns exemplos da presença da cultura em nossa vida: as leis que governam como um indivíduo pode ou deve se comportar em uma dada sociedade; o marketing que determina se uma 


\section{Infodesıgn}

campanha publicitária vai ser ou não focada em um público específico; ou um médico e as maneiras como este se comunica com seu paciente. Os conceitos de cultura e comunicação estão relacionados e regulam como as pessoas não apenas se comportam ou se expressam, mas também como elas formam uma mensagem e como outras pessoas respondem a essa mensagem.

Cultura e comunicação tornam-se então inseparáveis, onde a cultura é uma lente ou filtro pelo qual as pessoas recebem, interpretam e transmitem mensagens. Comunicação é também um sistema aberto e relacionado ao contexto cultural. Cultura atua como um ruído e pode interferir na habilidade do emissor na codificação da mensagem, que pode interferir na interpretação e na resposta dessa mensagem. Mensagens de texto, imagens e texto-imagem estão sujeitas as influências culturais durante o processo de aprendizado (Lange, 2000).

Na comunicação de informação sobre medicamentos, não apenas o fator cultural deve ser considerado, mas também os aspectos gráficos e de contexto de uso, pois a disseminação de informações acerca de medicamentos é um campo que atinge muitos grupos sociais diferentes em torno de uma mesma experiência (Cossio, 2005). Qualquer individuo pode vir a ficar doente e necessitar de medicamentos em seu tratamento, a qual pode ocorrer sob acompanhamento de profissionais da área de saúde ou não. Isso requer que informações sobre o uso de fármacos sejam disponibilizadas a todos. Porém, não basta estarem apenas disponíveis, elas devem estar compiladas de uma forma acessível e compreensível a todos os que dela necessitarem, independendo de seu grau de escolaridade, de sua classe social ou das circunstâncias em que se encontram.

No entanto, a acessibilidade das informações para medicamentos exige um nível elevado de compreensão e aderência junto a seus usuários (especialmente pelo fato de, muitas vezes, implicar riscos), de forma que esses produtos possam ser utilizados de forma mais efetiva e segura. Para que isso seja possível é necessário que todas as etapas do projeto de design da informação sejam executadas de uma forma completa e cuidadosa, prestando mais atenção em pontos fundamentais como: quem, onde e em quais circunstâncias vai utilizar o produto (contexto); o que é necessário saber para utilizar o produto de uma forma satisfatória (conteúdo informacional); e como transmitir essas informações da forma mais precisa possível (configuração visual). Além disso, a adequação as necessidades informacionais e perfil dos usuários no âmbito de medicamentos deve ocorrer não apenas na bula, mas também na comunicação de mensagens em geral sobre o tema, como no caso de campanhas educativas e informativas veiculadas na mídia.

\section{Metodologia}

O desenvolvimento dos instrumentos televisivos emprega metodologia teórico-analítica e pesquisa de campo considerando o estado da arte sobre comunicação televisiva de caráter social I utilidade pública e consulta a potencial público. Para a concepção e prototipagem do conjunto de filmes, foi preciso identificar as tendências deste tipo de mídia e as necessidades informacionais do público alvo. Para tanto, foram coletados dados quantitativa e qualitativamente através de: análise de similares, entrevista com o público-alvo e discussão com grupo focado. Os dados coletados subsidiaram a definição do conteúdo e da linguagem a serem adotados nos filmes.

\section{Análise de similares}

Para compor a amostra de similares foram coletados 105 filmes sendo 30 pertencentes a campanhas educativas; 40 governamentais informativas; 20 na área de Saúde; e 15 comerciais. Para a análise do material foi desenvolvido um modelo descritivo contemplando desde informações técnicas e gerais, componentes gráficos, a personagens e roteiro. Este foi aplicado em um filme amostra-tipo de cada campanha.

\section{Entrevista com público}

Após a análise de similares, foram realizadas entrevistas semi-estruturadas para identificar as percepções e expectativas do público em relação a uma campanha educativa para televisão abordando a relação dos participantes com bulas de medicamento; sua experiência e opinião sobre campanhas televisivas; e sua expectativa e preferência para uma campanha educativa na área de saúde. A entrevista foi conduzida individualmente com 30 adultos de ambos os sexos, com grau de escolaridade variado.

\section{Grupo focado}

Com o objetivo de complementar a pesquisa com dados qualitativos sobre a visão e necessidades do público em campanhas na área de saúde, foi conduzido um grupo focado (focus 
group) onde os participantes de forma interativa opinaram sobre uma amostra de seis filmes. Os participantes foram selecionados a partir de seu perfil, buscando abranger faixas etárias e graus de escolaridade variados. O roteiro do grupo focado foi desenvolvido com base na análise de similares, nos resultados das entrevistas e nos aspectos considerados no modelo C-HIP (Figura 2) proposto por Wogalter et al. (1999): atenção (a presença de uma informação pode ser notada ou não), compreensão (o valor dado à informação após esta ser examinada pelo receptor), atitudes e crenças (filtro cultural que ainda pode fazer com que a informação falhe), e motivação para mudar, ou não, o comportamento de acordo com a informação recebida. Cada estágio deste modelo permite que a informação siga para o próximo estágio ou bloqueie o fluxo de dados antes do término do processo.

Figura 2: Modelo C-HIP (Communication-human information processing) - Wogalter et al., 1999 apud Moraes, 2002.

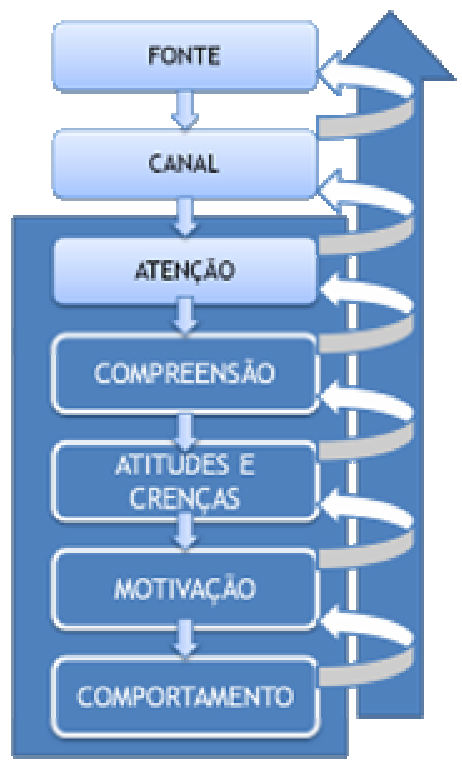

Os pontos de discussão foram intercalados com a apresentação de filmes (Figura 3), o que permitiu levantar questões envolvendo desde a experiência, opinião, preferência, percepção e considerações dos participantes acerca do tema. Essa discussão foi registrada em áudio e vídeo e posteriormente transcrita e analisada.

Figura 3: Imagem dos vídeos apresentados

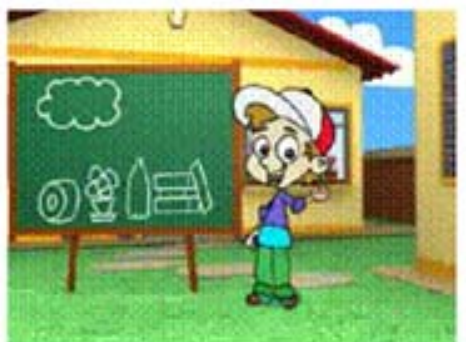

1. Campinas contra a dengue

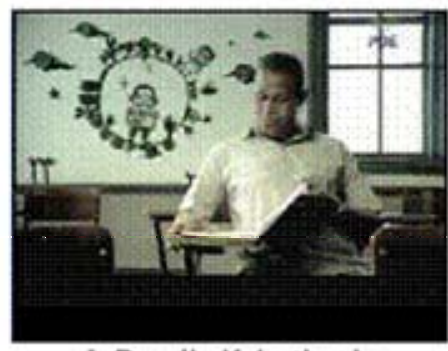

4. Brasil alfabetizado

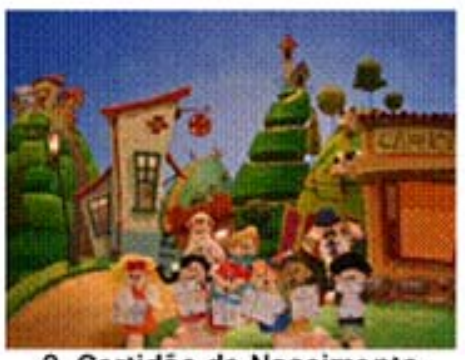

2. Certidâo de Nascimento

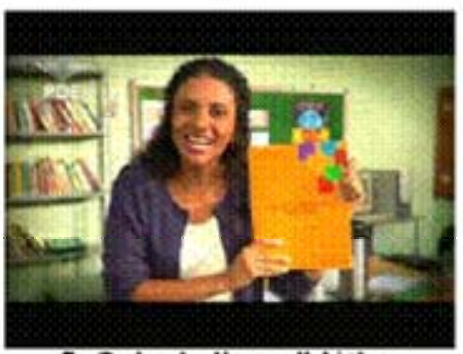

5. Guia do livro didático

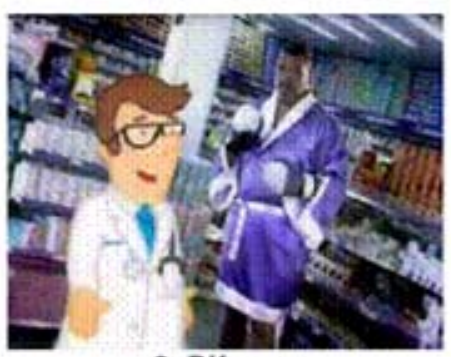

3. Bifarma

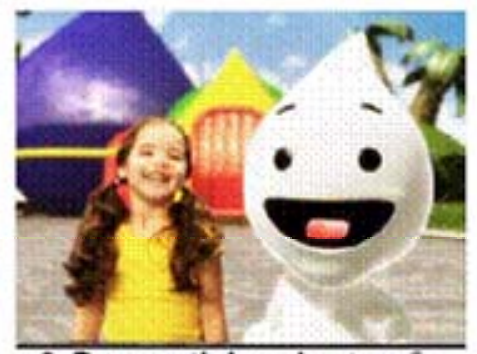

6. Duas gotinhas de atençáo 


\section{Infodesıgn}

\subsection{Síntese dos resultados e recomendações}

Os resultados mostraram na analise de similares que os filmes de campanhas, em geral: são curtos (30 segundos); utilizam redundância entre recursos visuais e sonoros (jingle, musica) para comunicar e fixar a mensagem desejada; e empregam slogan com frases curtas e sonoras. Já na entrevista e no grupo focado os resultados indicam de forma geral que as seguintes posições dos participantes sobre campanhas educativas: acham positiva a presença de mascote que represente a campanha; associam a seriedade da campanha a presença de personagens reais; consideram importante que essa comunicação apresente conteúdos e exemplos positivos do tema tratado. Por fim, no que se refere à postura dos participantes sobre campanhas na área de saúde e medicamentos, tem-se como expectativas: que esclareça sobre a bula de medicamentos, utilize a presença de profissionais de saúde para conferir autoridade e seriedade aos filmes, bem como a presença ativa de pacientes-usuários de medicamentos.

Com base nos resultados e na literatura estudada foram propostas algumas recomendações para o desenvolvimento da campanha:

\section{Sobre o conteúdo}

- Esclarecer dúvidas sobre bulas e medicamentos; apresentando as etapas corretas de aquisição e consumo de fármacos (prescrição, aquisição e uso);

- Informar sobre a leitura e interpretação corretas de bulas de medicamentos;

- Informar sobre mudanças na bula, para a nova regulamentação da ANVISA;

- Não sugerir conteúdo que leve a automedicação e a atitudes indesejadas em relação ao uso de medicamentos (hipocondria).

- Apresentar situações e exemplos positivos.

Sobre aspectos técnicos dos filmes (apresentação visual/sonora)

- Ter duração de 30 segundos;

- Utilizar-se de redundância, através do uso de mais de um meio para transmitir uma mesma mensagem (visual e sonoro);

- Ter participação de atores (ação livre);

- Usar animação (conteúdo animado);

- Apresentar como personagens: mascote (animação), médico, farmacêutico e paciente (atores);

- Apresentar indicação para o web site do projeto e da ANVISA

- Ter slogan simples e positivo.

Estas recomendações serviram para nortear a concepção e prototipagem do conjunto de filmes, brevemente descritos a seguir.

\section{Desenvolvimento dos filmes}

O desenvolvimento dos filmes para a campanha sobre medicamentos constou das etapas: (a) Pré-produção: definição do conteúdo específico; quantidade de filmes; elaboração de pré-roteiros e da linguagem dos filmes; e elaboração de storyboards; (b) Produção: filmagem do roteiro, produção de vinhetas, animações; e (c) Pós-produção: decupagem, edição sonora/áudio e de imagem, validação, ajustes e veiculação na mídia.

\section{(a) Pré-produção}

Com base nos dados da pesquisa e nos recursos disponíveis foi definido que a campanha seria composta de três filmes não seqüenciais e, para cada filme, foram estabelecidos os seguintes objetivos:

- Filme 01: A bula está mudando. Neste são apresentados os aspectos gráficos e de conteúdo que sofreram modificações na bula de acordo com as recomendações oriundas 
do Projeto InfoBula e constantes na ANVISA sobre o tema.

- Filme 02: Explicando a bula: Neste são apresentadas informações sobre o que consta na bula e que ela apresenta informações direcionadas a pacientes e farmacêuticos.

- Filme 03: Medicamentos e a bula: Neste e explicitado a seqüência de etapas para uso de medicamentos (receita, dispensação na farmácia e uso pelo paciente). São apresentadas também informações constantes na bula de interesse dos usuários: sobre uso, acondicionamento e descarte.

Definidos os objetivos, foram desenvolvidos os pré-roteiros, que consistem em descrição da linguagem e detalhamento do conteúdo de cada filme. Nesta etapa foram também desenvolvidas alternativas para a caracterização da personagem mascote da campanha, que seria uma Bula de Medicamentos animada (Figura 4).

Figura 4: Alternativas para a Mascote, sendo adotado o segundo desenho para a Campanha.
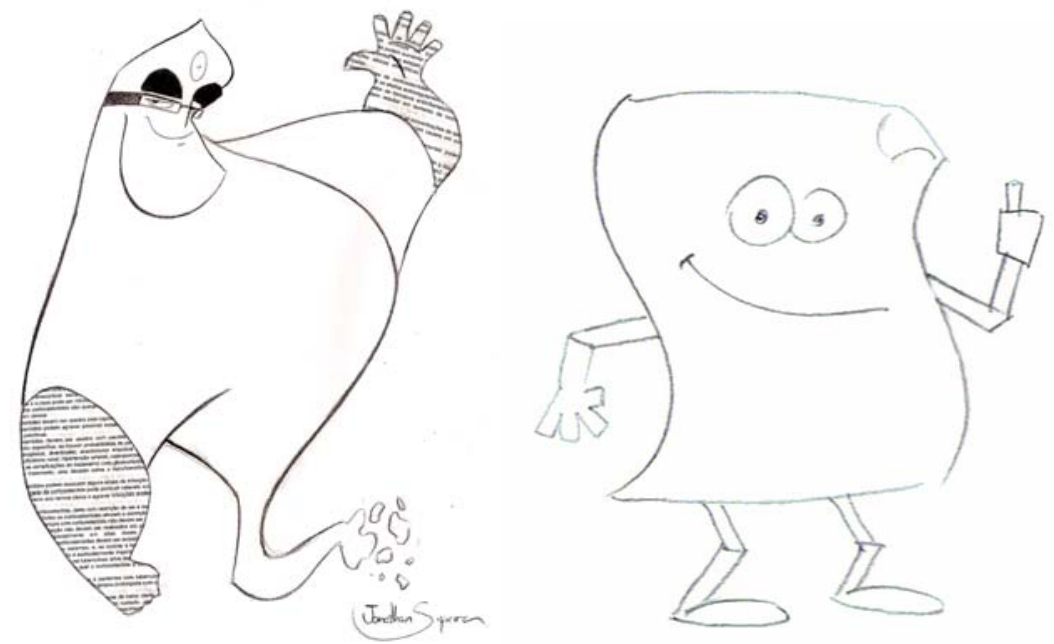

Em seguida foram elaborados storyboards para melhor visualização dos conteúdos dos filmes a serem produzidos, apresentando o roteiro desenhado com sinalização de temporização, falas, ações e personagens, conforme mostra a Figura 5.

Figura 5: Imagens do Storyboard 


\section{Infodesıgn}

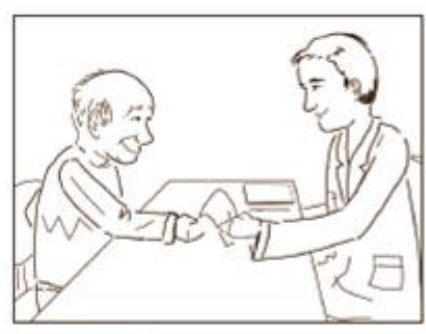

ÁUdio $3^{*}$

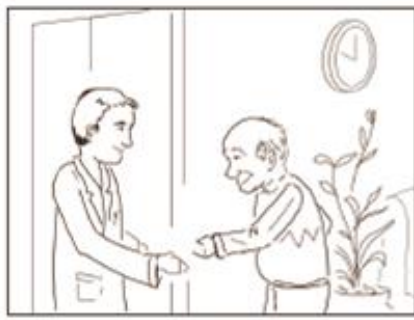

VIDEO

Consuttório médico, a camera enquadra um

médico entregando uma receita a um

senhor idoso que transmite

responsablidadce confians.

ÁUDIO 1"

VÍDEO

O medico despede-se e se afasta em

segundo plano

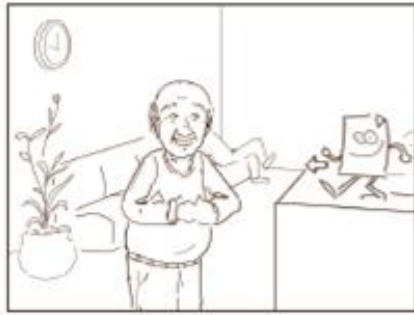

AUDIO 6"

Paciente

QUE A BULA MUDOU?

AGORA ESTA MAIS SIMPLES PARA VOCE

VIDEO

O paciente segue ate o balcào da

recepcionista. Entra em cena o mascote, que

interage com o personagem.

\section{(b) Produção}

Apos a definição dos roteiros e storyboards dos filmes da campanha, a mesma foi produzida em conjunto com o LAI-DI (Laboratório de Animação Interativa e Design da Informação) e uma produtora contratada.

\section{(c) Pós-produção}

Após a finalização dos filmes da campanha, estes foram validados junto ao público para verificar a compreensão e aceitação dos conteúdos e apresentação visual da campanha. Os testes para avaliação dos filmes produzidos foram realizados qualitativamente através de um novo grupo focado, que avaliou a compreensão das mensagens veiculadas e a satisfação dos participantes com as mesmas.

Os resultados desta validação mostraram que a campanha foi compreendida e bem aceita pelo público, e também permitiram ajustes necessários para aprimoramento dos filmes, tanto na animação, quanto na mascote e alguns ajustes técnicos na parte de ação.

A campanha produzida (Figura 6) será veiculada na Televisão Universitária da UFPR. Os filmes serão também disponibilizados para veiculação junto a ANVISA e Ministério da Saúde.

Figura 6: Imagens dos filmes produzidos
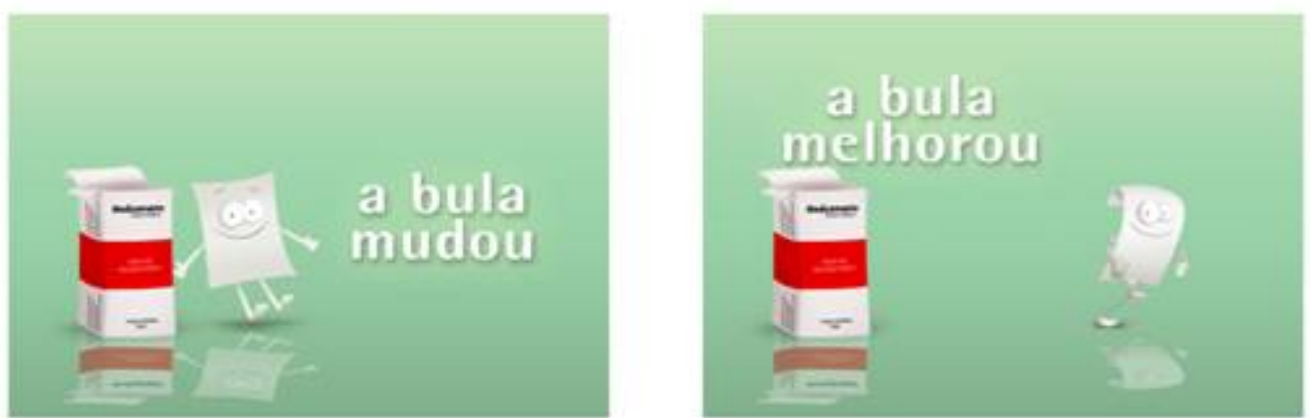

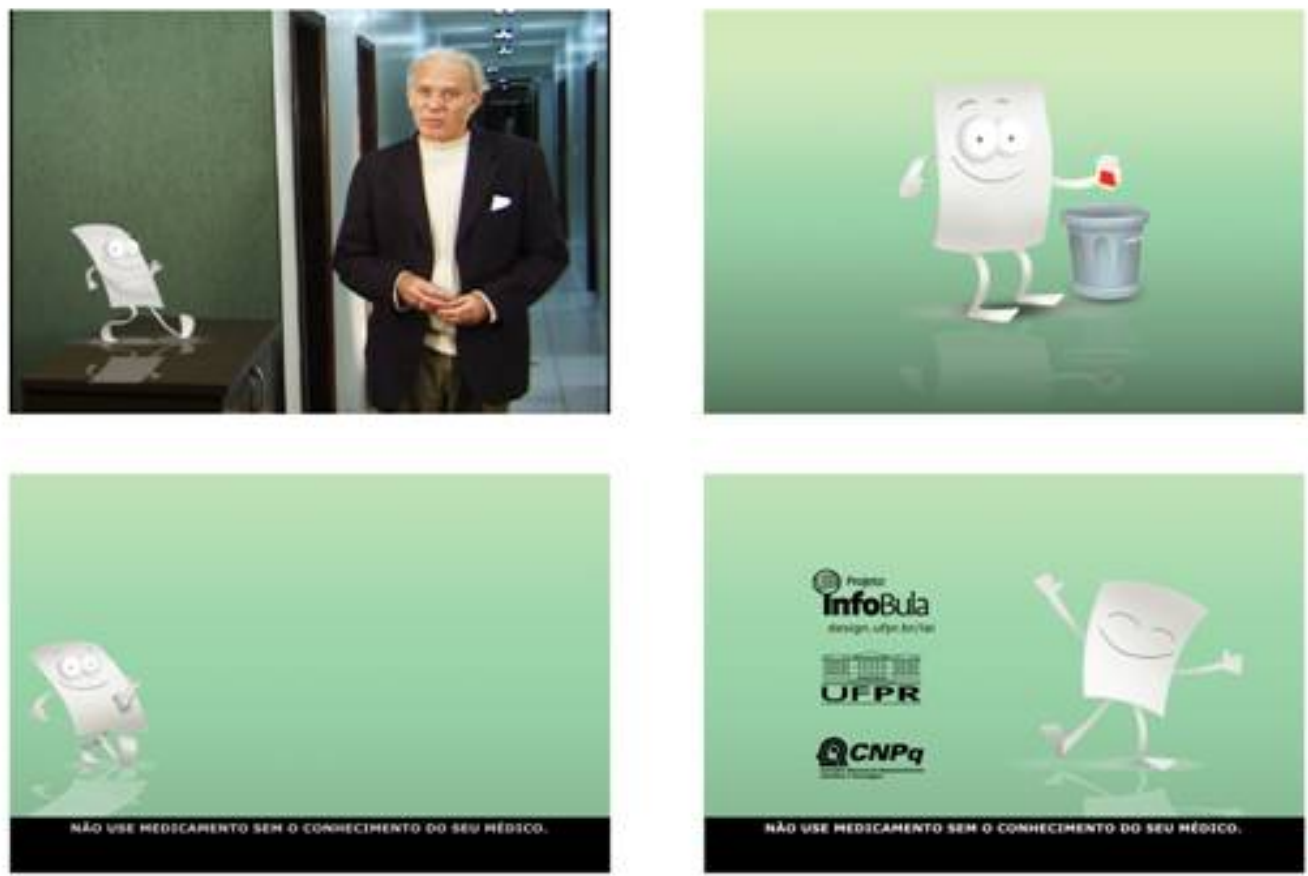

\section{Considerações finais}

Este artigo apresentou de forma sucinta uma abordagem multidisciplinar e centrada no usuário para a produção de filmes para campanha educativa na área de saúde no Brasil. Buscou-se assim, através desta abordagem a aplicação do design da informação à área de saúde e comunicação, e na disseminação de informação de interesse público. Com a conclusão deste projeto e veiculação de seus resultados, no caso os filmes, pretendeu-se contribuir para a produção de campanhas sociais em saúde que considerem o design da informação como elemento relevante na concepção de instrumentos televisivos, promovendo o conhecimento integrado e multidisciplinar.

Por fim, espera-se que os resultados do Projeto InfoBula possam servir a melhoria da formação e informação dos pacientes e usuários, promovendo a cidadania através da conscientização sobre a importância e o uso de bulas de medicamentos.

\section{Agradecimento}

Aos Profs. Carla G. Spinillo, pela orientação e Dras. Stephania Padovani e André L. Battaiola, pelo apoio. Ao CNPq pela bolsa de iniciação científica.

\section{Referências}

ANVISA. Resolução $n^{\circ} 140$ de 29 de maio de 2003. Estabelece regras das bulas de medicamentos para pacientes e profissionais da saúde. D.O.U. - Diário Oficial da União; Poder Executivo, de 02 de junho de 2003.

ASKEHAVE, Inger; ZETHSEN, Karen Korning. Communication Barriers in Public Discourse: The Patient Package Insert. Document Design. 2003, 4, 1, p. 23-41.

CossIO, M. G. Information Design for medicines in Mexico. Palestra proferida no $2^{\circ}$ Congresso Internacional de Design da Informação. São Paulo: Senac/Sociedade Brasileira de Design da Informação, 2005.

EDMUNDS, H. The focus group research handbook. Lincoln-wood, IL: NTC Business Books, 1999.

LANGE, Rudi W. de. Culture: a filtration process during communication in education, In: TEND 


\section{Infodesıgn}

2000: Proceedings of the Technological Education and National Development Conference, "Crossroads of the New Millennium" (2nd, April 8-10, 2000, Abu Dhabi, United Arab Emirates); see CE 080883.

TAKASHI Yamanoue, Michio Nakanishi, Atsushi Nakamura, Izumi Fuse, Ikuya Murata, Shozo Fukada, Takahiro Tagawa, Tatsumi Takeo, Shigeto Okabe, Tsuneo Yamada, Digital Video Clips Covering Computer Ethics in Higher Education, In Proceedings of the 33nd annual ACM SIGUCCS conference on User services, p.456-461, Monterey, California, US. 6-9 Nov. 2005.

WOGALTER, MS, Conzola, VC, \& Smith-Jackson, TL. Research-based guidelines for warning design and evaluation. Applied Ergonomics, 2002.

WZOREK, L. F. Avaliaçăo da qualidade das propagandas de medicamentos veiculadas em diferentes mídias e locais no estado do Paraná. Dissertação (Mestrado em Ciências Farmacêuticas). Curitiba: UFPR. 158p. 2005.

\section{Sobre o autor}

Cristiele A. Scariot, bacharelanda, UFPR. Aluna no Curso de Design Grfico da Universidade Federal do Paran, em Curitiba. Foi bolsista de iniciao cientfica por dois anos, quando desenvolveu este projeto.

cristiele@ibest.com.br 